\title{
Novel Time-of-Flight Residual Gas Analyzer (TOF-RGA) for in situ Real-time Process Monitoring
}

\author{
Sébastien Gasc* and Lukas Hofer
}

\begin{abstract}
Sensitive gas analyses, in particular in industrial processes, are nowadays performed either via spectroscopy or using quadrupole mass spectrometers; the first method provides a fast but indirect measurement, whereas the second provides in situ measurements of only one species at a time. In this article, we present a novel time-of-flight residual gas analyzer (TOF-RGA) built by the Swiss company Spacetek Technology AG, and show the results of measurements such as the characterization of the FC5311 calibration compound, the detection of naturally abundant noble gases in air, the measurement of a noble gas mixture in the ultra-high vacuum facilities of CERN, and measurements acquired in a X-ray Photoelectron Spectroscopy facility in Germany, to demonstrate the capability of this new TOF-RGA to compete with already existing techniques for the monitoring of the composition of gases in real time (10 times per second), at high resolution $(m / \Delta m=1200$ measured at $\mathrm{m} / \mathrm{z}$ 132), and with a high sensitivity at ppb level.
\end{abstract}

Keywords: Residual gas analysis · Time-of-flight mass spectrometry

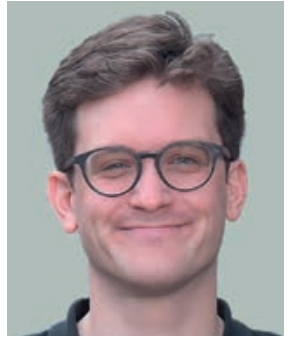

Sébastien Gasc received a MSc in Astronomical and Space-based Systems Engineering in Paris, France, and a $\mathrm{PhD}$ in Physics at the University of Bern, Switzerland. He worked on the ROSINA instruments aboard the ESA's Rosetta spacecraft, with focus on the time-of-flight mass spectrometer RTOF. After completing his $\mathrm{PhD}$, he worked as a calibration manager for the CLUPI instrument onboard the ESA's ExoMars Rover. In 2019, he joined Spacetek Technology AG, a spinoff company of the University of Bern, where he has been working on developing commercial time-of-flight mass spectrometers as a R\&D engineer and then as a Field Application Engineer.

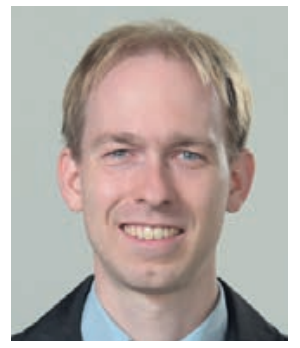

Lukas Hofer received a MSc and a $\mathrm{PhD}$ in Physics at the University of Bern, Switzerland. $\mathrm{He}$ worked on the time-of-flight mass spectrometer ROSINA/RTOF aboard the space mission Rosetta (ESA) and was involved in the compact Neutral Gas Mass Spectrometer (NGMS) aboard the Russian Luna-Resurs and Luna-Glob missions with focus on the development of the GC-MS interface for this instrument. After receiving his $\mathrm{PhD}$, he joined the Centre Suisse d'Électronique et de Microtechnique (CSEM), where he developed a new type of mass spectrometer for potential commercial applications. There he also gained experience with optical systems. In 2018 he co-founded the University of Bern spin-off company Spacetek Technology AG. Since then, he is developing commercial mass spectrometers and acts as CTO for the spin-off company.

\section{Introduction}

Many techniques exist to characterize and monitor industrial processes. While optical emission spectrometry is still widely used

${ }^{\star}$ Correspondence: Dr. S. Gasc, E-mail: sebastien.gasc@spacetek.ch Spacetek Technology AG, Brüggliweg 18, CH-3073 Gümligen in typical processes such as dry etching, either for characterization purposes $^{[1]}$ or for endpoint detection, ${ }^{[2]}$ mass spectrometry appears a viable alternative capable to provide in situ and realtime measurements of the composition of process gases. ${ }^{[3]}$

Quadrupole mass spectrometers have been used for many years to characterize the composition of gas mixtures, also in industrial processes such as dry etching, ${ }^{[4]}$ but lack the capability to provide an overview of a gas composition in real time, due to their inherent need to scan one mass at a time. Thanks to the progress of electronics, time-of-flight mass spectrometers such as the ones developed by Spacetek Technology AG, a Swiss spin-off company of the University of Bern incorporated in March 2018 in Muri-Gümligen (Bern, Switzerland), allow the quadrupole limitations to be overcome while at the same time relying on the well-known time-of-flight mass spectrometry technology.

In this work, we present the IonTamer ${ }^{\mathrm{TM}}$ products, which are the first time-of-flight residual gas analyzers (TOF-RGA) of their kind, and demonstrate some of their key characteristics such as (1) an extended mass range up to $m / z, 1200$, with the measurement of the heavy calibration compound FC5311, (2) a high sensitivity allowing the detection of species down to part-per-billion (ppb) levels, with the measurement of naturally abundant noble gases in air, (3) the capability to be quantitative also under very low pressure, down to a total pressure of at least $10^{-9}$ mbar, with measurements acquired in the ultra-high vacuum facilities of CERN, and (4) the capability to monitor an industrial process in real time, with measurements acquired in a X-ray photoelectron spectroscopy facility in Germany.

\section{IonTamer ${ }^{\mathrm{TM}}$ \\ 2.1 Time-of-Flight Technology}

Mass spectrometry is the ultimate analytical technique for the characterization of chemical composition in gaseous, liquid, and solid samples. Among the many types of mass spectrometers, time-of-flight mass spectrometers have gained traction in recent years for laboratory applications thanks to their high performance and mechanical robustness.

Time-of-flight mass spectrometers perform a separation of ionized species according to their ratio of mass to charge $(\mathrm{m} / \mathrm{z})$. 
With a linear time-of-flight mass spectrometer such as the one presented by Wiley and McLaren, ${ }^{[5]}$ the main steps required to achieve a separation of the ionized species are as follows:

1) ions are generated in an ion source from the neutral gas molecules located in its close vicinity;

2) these ions are accelerated to the same energy towards the mass analyzer, reaching different velocities due to differences in the mass of the ions;

3) the ions reach the detector where the ion current is converted to a numerical signal proportional to the number of ions generated in the ion source, allowing to measure both the flight time and the quantity of ions traveling through the mass analyzer.

4) A mass spectrum can be constructed, knowing the relation between the time of flight $t$ of a species and its mass $m$, as described in Eqn. (1):

$$
m=k \times\left(t-t_{0}\right)^{2}
$$

where $k$ and $t_{0}$ are constant parameters depending mostly on the geometry and the operating voltages of the mass analyzer.

Typical parameters used to characterize the performance of a mass spectrometer are:

1) the mass resolution, defined as $m / \Delta m,{ }^{[6]}$ where $\Delta \mathrm{m}$ is the peak width at $50 \%$ amplitude level (full width at half maximum), corresponding to the ability to separate ions with close mass,

2) the mass range, corresponding to the range of masses measurable by the instrument,

3) the sensitivity of the instrument to a specific species.

To further increase the performance of time-of-flight mass spectrometers, Karataev et al. ${ }^{[7]}$ and Mamyrin et al..$^{[8]}$ introduced the reflectron in 1972: acting as an ion mirror, it doubles the flight path of the ions in the drift region without increasing the instrument dimensions, thus directly increasing the mass resolution. In addition, it allows the correction of the time spread resulting from the initial thermal energy distribution in the ion source.

The principle of a time-of-flight mass spectrometer equipped with a reflectron is shown schematically in Fig. 1, together with an arbitrary example of a mass spectrum.

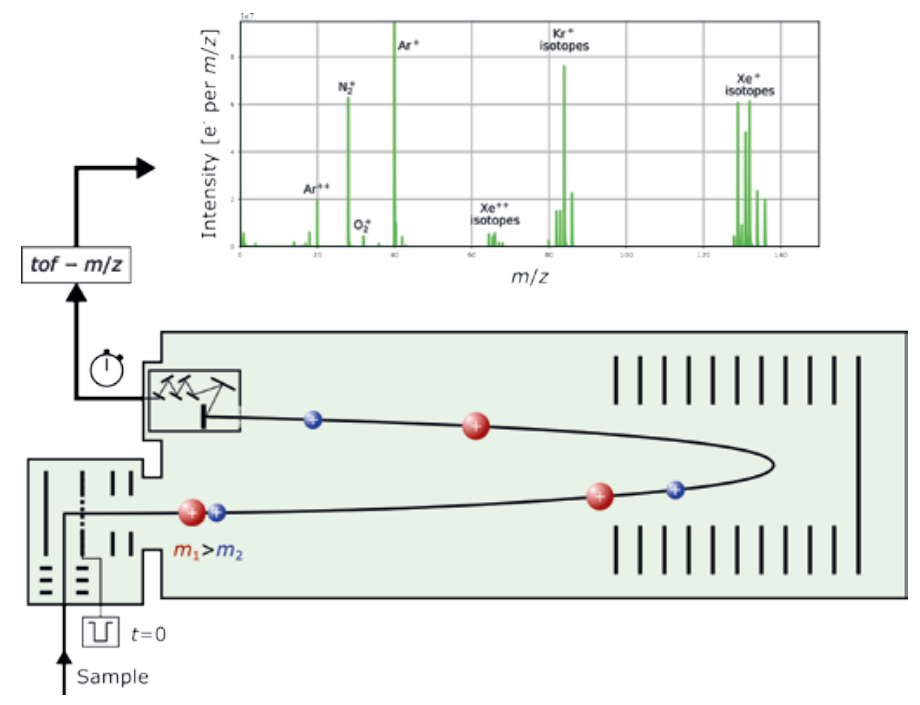

Fig. 1. Bottom: principle of a time-of-flight mass spectrometer with reflectron. Top: arbitrary mass spectrum acquired with a time-of-flight mass spectrometer. The $x$-axis shows the ratio of mass to charge $(\mathrm{m} / \mathrm{z})$ of the analyzed species; the $y$-axis shows a number of electrons per $\mathrm{m} / \mathrm{z}$ which is proportional to the number of ions generated in the ion source and therefore to the number of species in the investigated sample.

\subsection{Product Line}

Spacetek Technology's IonTamer ${ }^{\mathrm{TM}}$ instruments are time-offlight mass spectrometers equipped with a reflectron. Their ion source use either a tungsten or an yttria-coated iridium filament to ionize the gases in their vicinity by electron ionization, with a nominal ionization energy of $70 \mathrm{eV}$ (adjustable). The created ions undergo an orthogonal extraction ${ }^{[9]}$ at a frequency of $10 \mathrm{kHz}$ (for the measurements presented in this work) into the mass analyzer where they get separated according to their $\mathrm{m} / \mathrm{z}$, until they finally impact a polymer-free discrete-dynode electron multiplier which amplifies the ion signal. This signal is then accumulated to provide a histogram every $100 \mathrm{~ms}$. The IonTamer ${ }^{\mathrm{TM}}$ products measure all gas species from $\mathrm{m} / \mathrm{z}=1$ to $\mathrm{m} / \mathrm{z}=1200$, with a mass resolution $m / \Delta m$ of 1200 measured at $m / z=132$ (the mass resolution varies with $m / z$ as shown in Fig. 7).

The IonTamer ${ }^{\mathrm{TM}}$ residual gas analyzers are available in three configurations:

- Dive-In (DI)

- Flanged (FA)

- Pumping System (PS)

An additional harsh version $(-\mathrm{H})$ exists for each configuration (e.g. IonTamer $\left.{ }^{\mathrm{TM}} \mathrm{PS}-\mathrm{H}\right)$, built for the use in aggressive manufacturing processes, such as dry etching.

The DI and FA configurations are operated in a pressure range up to $1 \cdot 10^{-5}$ mbar. The DI instruments are inserted $40 \mathrm{~cm}$ directly into the customer's vacuum chambers on a standard CF100 flange, whereas the FA instruments are placed outside the customer's vacuum chamber and connected via a commonly available CF40 flange (see Fig. 2).

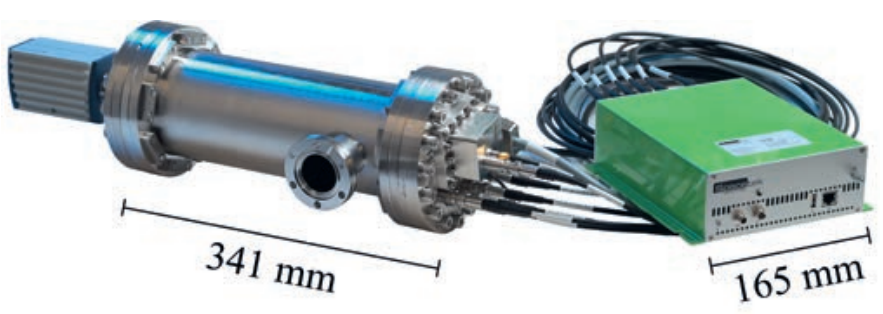

Fig. 2. IonTamer ${ }^{\mathrm{TM}} \mathrm{FA}$ with electronics.

The PS instruments (shown in Fig. 3) are equipped with a turbomolecular pump with a pumping speed of $67 \mathrm{l} / \mathrm{s}\left(\mathrm{N}_{2}\right)$, allowing them to be operated within a much larger pressure range, up to atmospheric pressure or even higher. The PS version also allows various inlet system adaptations.

\subsection{Application Examples}

The IonTamer ${ }^{\mathrm{TM}}$ products aim at redefining process and product quality by bringing time-of-flight technology in the following fields:

- wafer manufacturing,

- OLED-display manufacturing,

- environmental science research,

- industrial vacuum coating.

In the following paragraphs, we present application examples that demonstrate key features of the IonTamer ${ }^{\mathrm{TM}}$ products, making them an asset in the fields listed above, such as an extended mass range up to $m / z=1200$ and a high mass resolution $(\mathrm{m} / \Delta m=1200$ for xenon) with respect to their form factor (section 2.3.1), a high sensitivity (sections $2.3 .2,2.3 .4$ ), a large operating pressure range up to more than 1 bar (sections 2.3.2, 2.3.3), the ability to control 


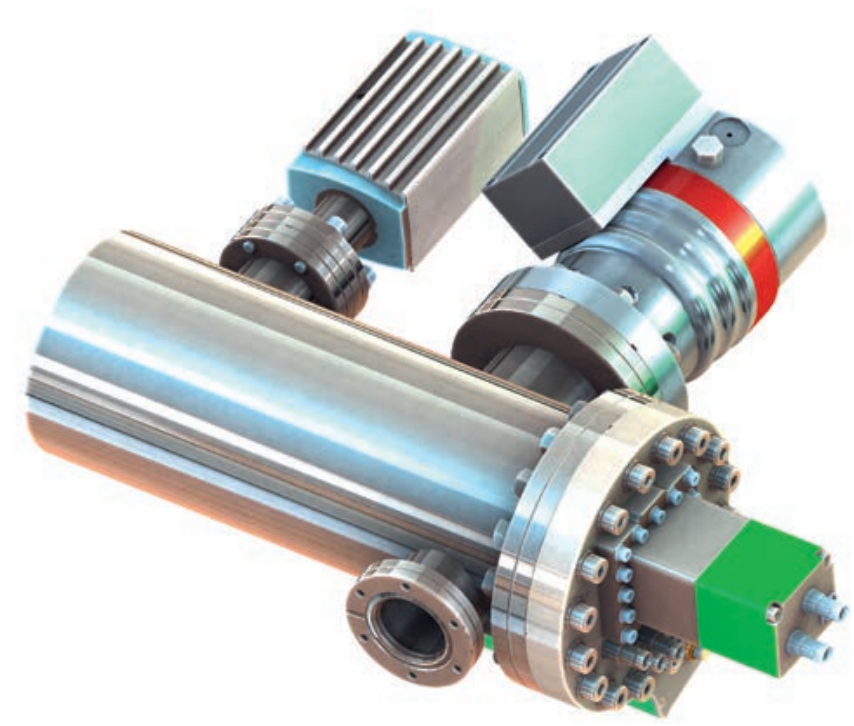

Fig. 3. IonTamer'M PS.

processes in real time (section 2.3.4), and in general the capability to measure all species simultaneously within the IonTamer ${ }^{\mathrm{TM}}$ 's mass range, i.e. up to $\mathrm{m} / \mathrm{z}=1200$.

\subsubsection{High Mass Calibration Reference with FC5311}

The FC5311 calibration liquid is a well-known high molecular weight compound used for the calibration of mass spectrometers. It contains perfluorophenanthrene $\left(\mathrm{C}_{14} \mathrm{~F}_{24}\right)$ which has a molecular weight of $624.1115 \mathrm{Da}$. Its molecular structure is shown in Fig. 4.

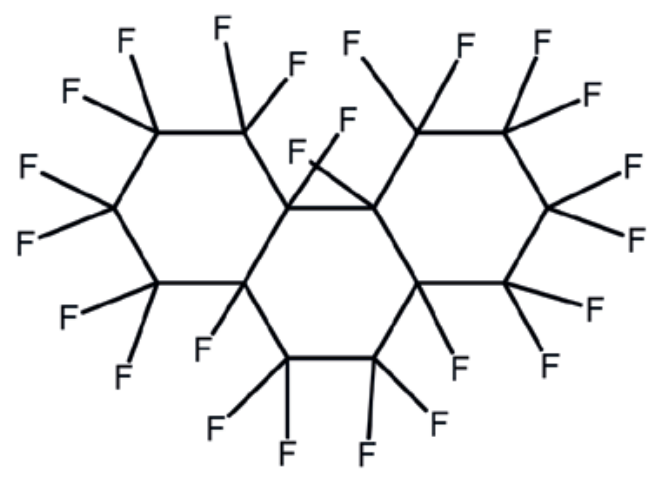

Fig. 4. Perfluorophenanthrene $\left(\mathrm{C}_{14} \mathrm{~F}_{24}\right)$ molecular structure.

To compare with already existing measurements performed with magnetic sector mass spectrometers, ${ }^{[10]}$ FC5311 has been measured with an IonTamerTM $\mathrm{FA}$ at ambient temperature $\left(20^{\circ} \mathrm{C}\right)$ under a pressure of $1 \cdot 10^{-5} \mathrm{mbar}$ in the ion source, sampling from the headspace of the FC5311 liquid. The mass spectrum resulting from this measurement is presented in Fig. 5, and the identified fragments are listed in Table 1. Please note that due to isobaric interferences, minor species originating, for example, from recombinations might not be listed due to their close proximity in $\mathrm{m} / \mathrm{z}$ with more abundant fragments of the FC5311 compound.

All fragments listed in the literature ${ }^{[10]}$ have been successfully identified with the IonTamer ${ }^{\mathrm{TM}} \mathrm{FA}$ instrument with the exception of three species reported at $\mathrm{m} / \mathrm{z}, 55,56$, and 57; a signal at these $m / z$ was nevertheless not expected, as no simple fragments of the FC5311 can be expected with such $\mathrm{m} / \mathrm{z}$ values. Many additional fragments (99 in the number) with low abundances are, on the other hand, additionally identified due to the high sensitivity of the IonTamer ${ }^{\mathrm{TM}}$ FA instruments. In particular, some fragments with masses heavier than the parent molecule (i.e. higher than $\mathrm{m} / \mathrm{z}$ 624) are identified, corresponding to the capture of either one or three additional fluorine atoms by the $\mathrm{C}_{14} \mathrm{~F}_{24}{ }^{+}$ion, made possible by the weakening of carbon bonds in the molecule's rings due to electron ionization. Other recombinations with atoms such as $\mathrm{O}$ and $\mathrm{H}$ are observed additionally, originating from the residual gas molecules in the vacuum chamber (e.g. CFO (46.99 Da), $\mathrm{CHF}_{2}(51.00 \mathrm{Da})$, $\left.\mathrm{CF}_{2} \mathrm{O}(65.99 \mathrm{Da})\right)$.
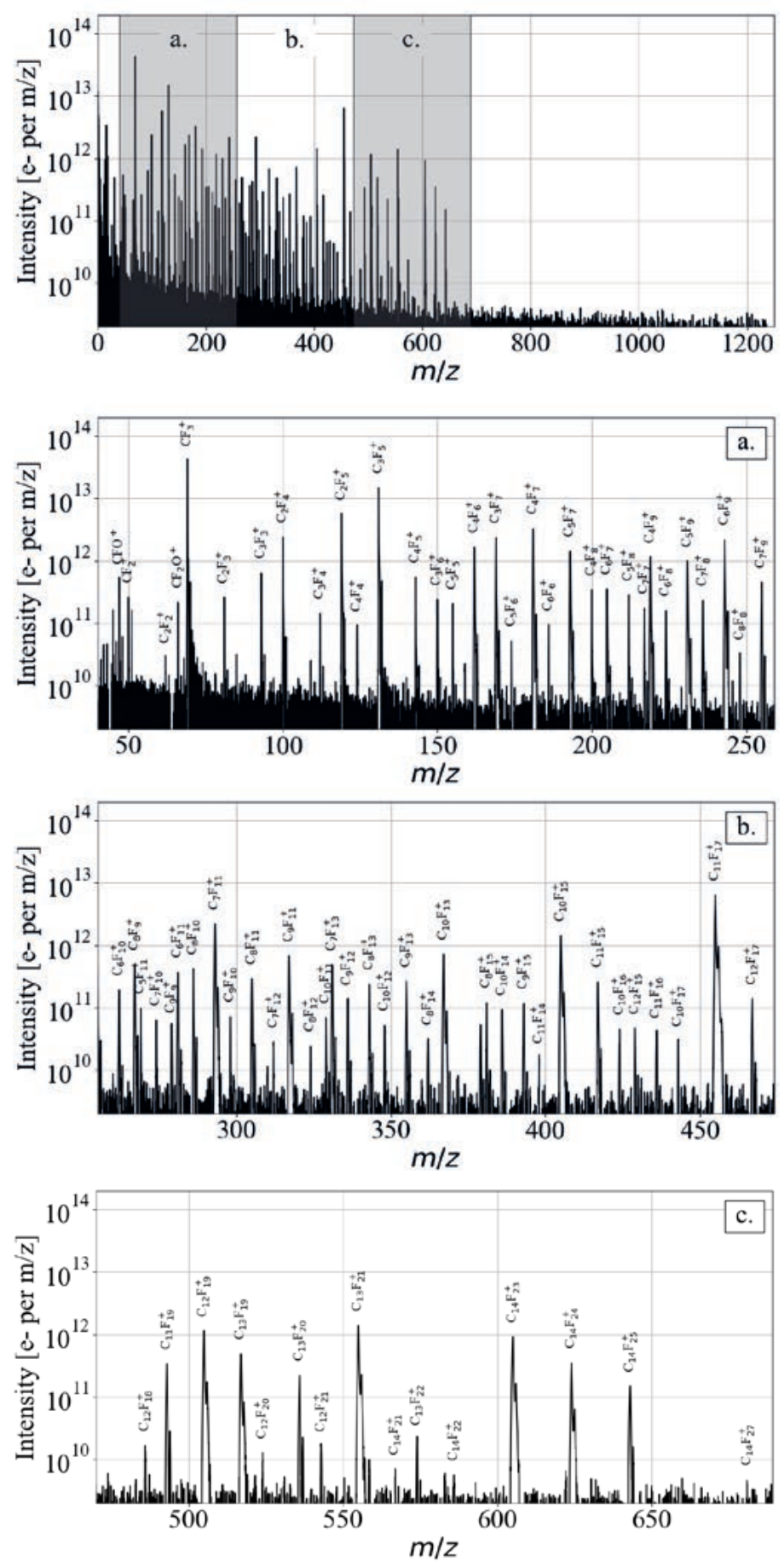

Fig. 5. Top: FC5311 mass spectrum acquired with an IonTamer ${ }^{\text {TM }}$ FA (electron ionization with $70 \mathrm{eV}, 180 \mathrm{~s}$ integration time); a, b, c: zooms on the regions of interest. The peak visible on the right side of each fragment belongs to the isotopologue located on the first consecutive mass, where $\mathrm{a}^{13} \mathrm{C}$ atom replaces one ${ }^{12} \mathrm{C}$. 
Table 1. Fragmentation table for FC5311 acquired with the lonTamer TM FA. Compounds also identified in literature ${ }^{[10]}$ are highlighted in bold font. Theoretical masses have been calculated based on the CIAAW Standard Atomic Weights; ${ }^{[11]}$ the mass of an electron has been subtracted.

\begin{tabular}{|c|c|c|c|c|c|c|c|c|c|}
\hline Formula & $m / z$ & Formula & $\mathrm{m} / \mathrm{z}$ & Formula & $m / z$ & Formula & $m / z$ & Formula & $m / z$ \\
\hline $\mathrm{C}^{+}$ & 11.9995 & $\mathrm{C}_{4} \mathrm{~F}_{6}^{+}$ & 161.9899 & $\mathrm{C}_{6} \mathrm{~F}_{9}^{+}$ & 242.9851 & $\mathrm{C}_{7} \mathrm{~F}_{13}{ }^{+}$ & 330.9787 & $\mathrm{C}_{11} \mathrm{~F}_{17}{ }^{+}$ & 454.9723 \\
\hline $\mathrm{F}^{+}$ & 18.9979 & ${ }^{13} \mathrm{CC}_{3} \mathrm{~F}_{6}^{+}$ & 162.9932 & ${ }^{13} \mathrm{CC}_{5} \mathrm{~F}_{9}^{+}$ & 243.9884 & ${ }^{13} \mathrm{CC}_{6} \mathrm{~F}_{13}{ }^{+}$ & 331.9820 & $\mathrm{C}_{12} \mathrm{~F}_{17}^{+}$ & 466.9723 \\
\hline $\mathrm{CF}^{+}$ & 30.9979 & $\mathrm{C}_{3} \mathbf{F}_{7}^{+}$ & 168.9883 & $\mathrm{C}_{8} \mathrm{~F}_{8}^{+}$ & 247.9867 & $\mathrm{C}_{9} \mathrm{~F}_{12}{ }^{+}$ & 335.9803 & ${ }^{13} \mathrm{CC}_{11} \mathrm{~F}_{17}^{+}$ & 467.9757 \\
\hline $\mathrm{CFO}^{+}$ & 46.9928 & ${ }^{13} \mathrm{CC}_{2} \mathrm{~F}_{7}^{+}$ & 169.9916 & $\mathrm{C}_{7} \mathrm{~F}_{9}^{+}$ & 254.9851 & ${ }^{13} \mathrm{CC}_{8} \mathrm{~F}_{12}{ }^{+}$ & 336.9836 & $\mathrm{C}_{12} \mathrm{~F}_{18}^{+}$ & 485.9707 \\
\hline $\mathrm{CF}_{2}^{+}$ & 49.9963 & $\mathrm{C}_{5} \mathrm{~F}_{6}^{+}$ & 173.9899 & ${ }^{13} \mathrm{CC}_{6} \mathrm{~F}_{9}^{+}$ & 255.9884 & $\mathrm{C}_{8} \mathrm{~F}_{13}{ }^{+}$ & 342.9787 & $\mathrm{C}_{11} \mathrm{~F}_{19}{ }^{+}$ & 492.9691 \\
\hline $\mathrm{CHF}_{2}^{+}$ & 51.0041 & $\mathrm{C}_{4} \mathrm{~F}_{7}^{+}$ & 180.9883 & $\mathrm{C}_{6} \mathrm{~F}_{10}{ }^{+}$ & 261.9835 & ${ }^{13} \mathrm{CC}_{7} \mathrm{~F}_{13}{ }^{+}$ & 343.9820 & ${ }^{13} \mathrm{CC}_{10} \mathrm{~F}_{19}^{+}$ & 493.9725 \\
\hline $\mathrm{C}_{2} \mathrm{~F}_{2}^{+}$ & 61.9963 & ${ }^{13} \mathrm{CC}_{3} \mathrm{~F}_{7}^{+}$ & 181.9916 & ${ }^{13} \mathrm{CC}_{5} \mathrm{~F}_{10}{ }^{+}$ & 262.9868 & $\mathrm{C}_{10} \mathrm{~F}_{12}{ }^{+}$ & 347.9803 & $\mathrm{C}_{12} \mathrm{~F}_{19}{ }^{+}$ & 504.9691 \\
\hline $\mathrm{CF}_{2} \mathrm{O}^{+}$ & 65.9912 & $\mathrm{C}_{6} \mathrm{~F}_{6}^{+}$ & 185.9899 & $\mathrm{C}_{8} \mathrm{~F}_{9}^{+}$ & 266.9851 & $\mathrm{C}_{9} \mathrm{~F}_{13}{ }^{+}$ & 354.9787 & ${ }^{13} \mathrm{CC}_{11} \mathrm{~F}_{19}^{+}$ & 505.9725 \\
\hline $\mathrm{CF}_{3}^{+}$ & 68.9947 & ${ }^{13} \mathrm{CC}_{5} \mathrm{~F}_{6}^{+}$ & 186.9932 & ${ }^{13} \mathrm{CC}_{7} \mathrm{~F}_{9}^{+}$ & 267.9884 & ${ }^{13} \mathrm{CC}_{8} \mathrm{~F}_{13}{ }^{+}$ & 355.9820 & $\mathrm{C}_{13} \mathrm{~F}_{19}{ }^{+}$ & 516.9691 \\
\hline${ }^{13} \mathrm{CF}_{3}^{+}$ & 69.9980 & $\mathrm{C}_{5} \mathbf{F}_{7}^{+}$ & 192.9883 & $\mathrm{C}_{5} \mathrm{~F}_{11}{ }^{+}$ & 268.9819 & $\mathrm{C}_{8} \mathrm{~F}_{14}{ }^{+}$ & 361.9771 & ${ }^{13} \mathrm{CC}_{12} \mathrm{~F}_{19}^{+}$ & 517.9725 \\
\hline $\mathrm{C}_{2} \mathrm{~F}_{3}^{+}$ & 80.9947 & ${ }^{13} \mathrm{CC}_{4} \mathrm{~F}_{7}^{+}$ & 193.9916 & $\mathrm{C}_{7} \mathrm{~F}_{10}{ }^{+}$ & 273.9835 & $\mathrm{C}_{10} \mathrm{~F}_{13}^{+}$ & 366.9787 & $\mathrm{C}_{12} \mathrm{~F}_{20}{ }^{+}$ & 523.9675 \\
\hline $\mathrm{C}_{3} \mathbf{F}_{3}^{+}$ & 92.9947 & $\mathrm{C}_{4} \mathrm{~F}_{8}^{+}$ & 199.9867 & $\mathrm{C}_{9} \mathrm{~F}_{9}^{+}$ & 278.9851 & ${ }^{13} \mathrm{CC}_{9} \mathrm{~F}_{13}{ }^{+}$ & 367.9820 & $\mathrm{C}_{13} \mathrm{~F}_{20}^{+}$ & 535.9675 \\
\hline${ }^{13} \mathrm{CC}_{2} \mathrm{~F}_{3}^{+}$ & 93.9980 & ${ }^{13} \mathrm{CC}_{3} \mathrm{~F}_{8}^{+}$ & 200.9900 & $\mathrm{C}_{6} \mathrm{~F}_{11}{ }^{+}$ & 280.9819 & $\mathrm{C}_{11} \mathrm{~F}_{13}^{+}$ & 378.9787 & ${ }^{13} \mathrm{CC}_{12} \mathrm{~F}_{20}{ }^{+}$ & 536.9709 \\
\hline $\mathrm{C}_{2} \mathbf{F}_{4}^{+}$ & 99.9931 & $\mathrm{C}_{6} \mathrm{~F}_{7}^{+}$ & 204.9883 & ${ }^{13} \mathrm{CC}_{5} \mathrm{~F}_{11}{ }^{+}$ & 281.9852 & $\mathrm{C}_{8} \mathrm{~F}_{15}{ }^{+}$ & 380.9755 & $\mathrm{C}_{12} \mathrm{~F}_{21}^{+}$ & 542.9659 \\
\hline${ }^{13} \mathrm{CCF}_{4}^{+}$ & 100.9964 & ${ }^{13} \mathrm{CC}_{5} \mathrm{~F}_{7}^{+}$ & 205.9916 & $\mathrm{C}_{8} \mathrm{~F}_{10}{ }^{+}$ & 285.9835 & ${ }^{13} \mathrm{CC}_{7} \mathrm{~F}_{15}{ }^{+}$ & 381.9789 & $\mathrm{C}_{13} \mathrm{~F}_{21}{ }^{+}$ & 554.9659 \\
\hline $\mathrm{C}_{3} \mathbf{F}_{4}^{+}$ & 111.9931 & $\mathrm{C}_{5} \mathrm{~F}_{8}^{+}$ & 211.9867 & ${ }^{13} \mathrm{CC}_{7} \mathrm{~F}_{10}{ }^{+}$ & 286.9868 & $\mathrm{C}_{10} \mathrm{~F}_{14}^{+}$ & 385.9771 & ${ }^{13} \mathrm{CC}_{12} \mathrm{~F}_{21}^{+}$ & 555.9693 \\
\hline $\mathrm{C}_{2} \mathbf{F}_{5}^{+}$ & 118.9915 & ${ }^{13} \mathrm{CC}_{4} \mathrm{~F}_{8}^{+}$ & 212.9900 & $\mathrm{C}_{7} \mathbf{F}_{11}{ }^{+}$ & 292.9819 & ${ }^{13} \mathrm{CC}_{9} \mathrm{~F}_{14}{ }^{+}$ & 386.9805 & $\mathrm{C}_{14} \mathrm{~F}_{21}^{+}$ & 566.9659 \\
\hline${ }^{13} \mathrm{CCF}_{5}^{+}$ & 119.9948 & $\mathbf{C}_{7} \mathbf{F}_{7}^{+}$ & 216.9883 & ${ }^{13} \mathrm{CC}_{6} \mathrm{~F}_{11}^{+}$ & 293.9852 & $\mathrm{C}_{9} \mathrm{~F}_{15}{ }^{+}$ & 392.9755 & $\mathrm{C}_{13} \mathrm{~F}_{22}^{+}$ & 573.9643 \\
\hline $\mathrm{C}_{4} \mathbf{F}_{4}^{+}$ & 123.9931 & ${ }^{13} \mathrm{CC}_{6} \mathrm{~F}_{7}^{+}$ & 217.9916 & $\mathrm{C}_{9} \mathrm{~F}_{10}{ }^{+}$ & 297.9835 & $\mathrm{C}_{11} \mathrm{~F}_{14}^{+}$ & 397.9771 & ${ }^{13} \mathrm{CC}_{12} \mathrm{~F}_{22}{ }^{+}$ & 574.9677 \\
\hline $\mathrm{C}_{3} \mathrm{~F}_{5}^{+}$ & 130.9915 & $\mathrm{C}_{4} \mathbf{F}_{9}^{+}$ & 218.9851 & $\mathrm{C}_{8} \mathrm{~F}_{11}{ }^{+}$ & 304.9819 & $\mathrm{C}_{10} \mathrm{~F}_{15}{ }^{+}$ & 404.9755 & $\mathrm{C}_{14} \mathrm{~F}_{22}^{+}$ & 585.9643 \\
\hline${ }^{13} \mathrm{CC}_{2} \mathrm{~F}_{5}^{+}$ & 131.9948 & ${ }^{13} \mathrm{CC}_{3} \mathrm{~F}_{9}^{+}$ & 219.9884 & ${ }^{13} \mathrm{CC}_{7} \mathrm{~F}_{11}{ }^{+}$ & 305.9852 & ${ }^{13} \mathrm{CC}_{9} \mathrm{~F}_{15}{ }^{+}$ & 405.9789 & $\mathrm{C}_{14} \mathrm{~F}_{23}{ }^{+}$ & 604.9627 \\
\hline $\mathrm{C}_{4} \mathrm{~F}_{5}^{+}$ & 142.9915 & $\mathrm{C}_{6} \mathrm{~F}_{8}^{+}$ & 223.9867 & $\mathrm{C}_{10} \mathrm{~F}_{10}{ }^{+}$ & 309.9835 & $\mathrm{C}_{11} \mathrm{~F}_{15}^{+}$ & 416.9755 & ${ }^{13} \mathrm{CC}_{13} \mathrm{~F}_{23}^{+}$ & 605.9661 \\
\hline${ }^{13} \mathrm{CC}_{3} \mathrm{~F}_{5}{ }^{+}$ & 143.9948 & ${ }^{13} \mathrm{CC}_{5} \mathrm{~F}_{8}^{+}$ & 224.9900 & $\mathrm{C}_{7} \mathrm{~F}_{12}{ }^{+}$ & 311.9803 & ${ }^{13} \mathrm{CC}_{10} \mathrm{~F}_{15}{ }^{+}$ & 417.9789 & $\mathrm{C}_{14} \mathrm{~F}_{24}{ }^{+}$ & 623.9611 \\
\hline $\mathrm{C}_{3} \mathrm{~F}_{6}^{+}$ & 149.9899 & $\mathrm{C}_{5} \mathrm{~F}_{9}^{+}$ & 230.9851 & $\mathrm{C}_{9} \mathrm{~F}_{11}{ }^{+}$ & 316.9819 & $\mathrm{C}_{10} \mathrm{~F}_{16}^{+}$ & 423.9739 & ${ }^{13} \mathrm{CC}_{13} \mathrm{~F}_{24}{ }^{+}$ & 624.9645 \\
\hline${ }^{13} \mathrm{CC}_{2} \mathrm{~F}_{6}^{+}$ & 150.9932 & ${ }^{13} \mathrm{CC}_{4} \mathrm{~F}_{9}{ }^{+}$ & 231.9884 & ${ }^{13} \mathrm{CC}_{8} \mathrm{~F}_{11}^{+}$ & 317.9852 & $\mathrm{C}_{12} \mathrm{~F}_{15}{ }^{+}$ & 428.9755 & $\mathrm{C}_{14} \mathrm{~F}_{25}^{+}$ & 642.9595 \\
\hline $\mathbf{C}_{5} \mathbf{F}_{5}^{+}$ & 154.9915 & $\mathrm{C}_{7} \mathrm{~F}_{8}^{+}$ & 235.9867 & $\mathrm{C}_{8} \mathrm{~F}_{12}^{+}$ & 323.9803 & $\mathrm{C}_{11} \mathrm{~F}_{16}^{+}$ & 435.9739 & ${ }^{13} \mathrm{CC}_{13} \mathrm{~F}_{25}{ }^{+}$ & 643.9629 \\
\hline${ }^{13} \mathrm{CC}_{4} \mathrm{~F}_{5}^{+}$ & 155.9948 & ${ }^{13} \mathrm{CC}_{6} \mathrm{~F}_{8}^{+}$ & 236.9900 & $\mathrm{C}_{10} \mathrm{~F}_{11}^{+}$ & 328.9819 & $\mathrm{C}_{10} \mathrm{~F}_{17}{ }^{+}$ & 442.9723 & $\mathrm{C}_{14} \mathrm{~F}_{27}{ }^{+}$ & 680.9563 \\
\hline
\end{tabular}

Fig. 6 shows the ratio of the measured relative abundances over the literature values. A general trend is observed, indicating a higher sensitivity for the high masses: as the IonTamer ${ }^{\mathrm{TM}}$ instruments use orthogonal extraction, ${ }^{[9]}$ the duty cycle increases with increasing $\mathrm{m} / \mathrm{z}$, and so does the transmission for the heavier masses. Furthermore, the relative kinetic energy spread of the ions is reduced and detection efficiency of the detector for heavy masses is increased by post-acceleration.

The many masses observed in the spectrum have also been used to produce Fig. 7, which shows the evolution of the mass resolution with the increasing $\mathrm{m} / \mathrm{z}$.

This measurement illustrates one main advantage of the IonTamer ${ }^{\mathrm{TM}}$ instruments and of the time-of-flight mass spectrometry technology in general: the possibility to observe the full mass range up to $\mathrm{m} / \mathrm{z}, 1200$ at once without scanning the mass range, allowing to possibly detect unexpected compounds.

\subsubsection{PPB Detection of Natural Noble Gases in Air}

Helium (He), neon (Ne), argon (Ar), krypton (Kr), and xenon (Xe) are colorless, odorless, monoatomic noble gases found in the
Earth's atmosphere with abundances relative to air ranging from about $1 \%(\mathrm{Ar})$ through to a few parts per million (ppm) (He, Kr) and a few tens of parts per billion (ppb) (Xe).

Their very low chemical reactivity together with their unique isotopic features make these noble gases good candidates to

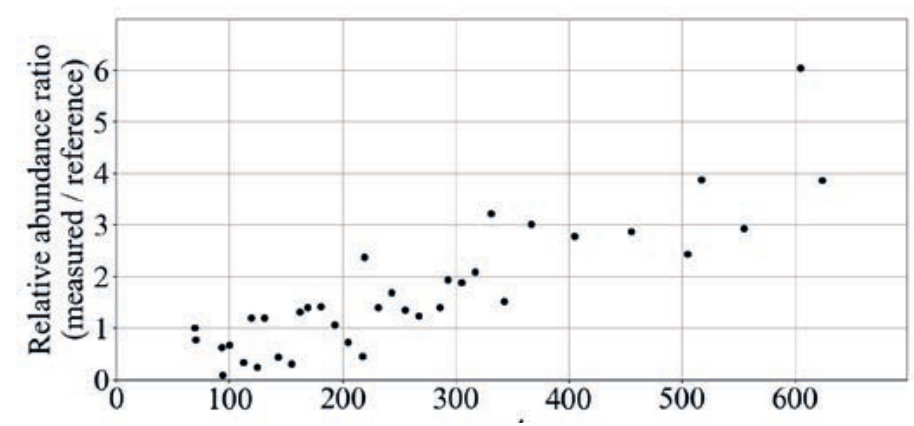

Fig. 6. Trend between relative abundances measured with IonTamer ${ }^{\mathrm{TM}}$ over literature values ${ }^{[10]}$ with increasing mass range. 


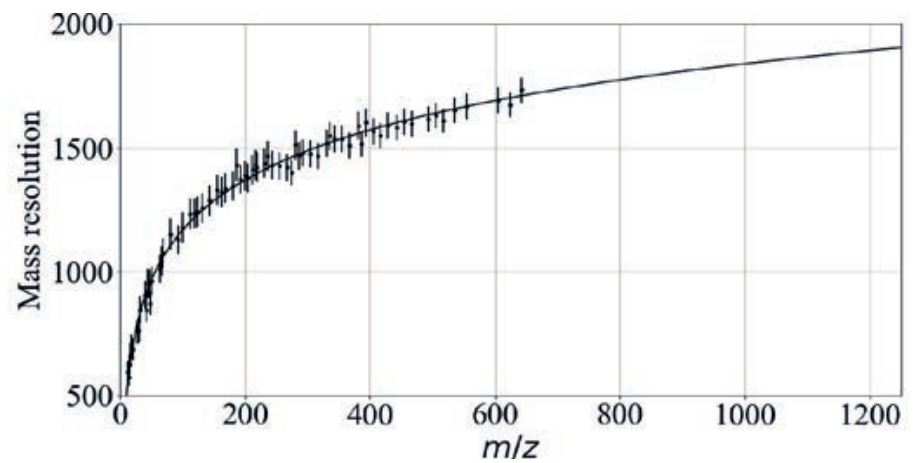

Fig. 7. Mass resolution versus $m / z$ of the lonTamer ${ }^{\mathrm{TM}}$ instruments.

demonstrate the capabilities of the IonTamer ${ }^{\mathrm{TM}} \mathrm{PS}-\mathrm{H}$ to identify and quantify species in trace amounts.

The IonTamer ${ }^{\mathrm{TM}} \mathrm{PS}-\mathrm{H}$ measured room air at ambient temperature $\left(20{ }^{\circ} \mathrm{C}\right)$ during $2 \mathrm{~h} 47 \mathrm{~min}$, under a pressure of 2.0 $10^{-3}$ mbar in the ion source, in High Emission (electron ionization at $2 \mathrm{~mA}$ and $70 \mathrm{eV}$ ), and in High Gain mode (i.e. with increased detector gain of a factor of ten). The resulting mass spectrum is shown in Fig. 8. Due to their low abundance compared with the other species, the krypton and xenon isotopes are separately shown in Fig. 9 and in Fig. 10, respectively.

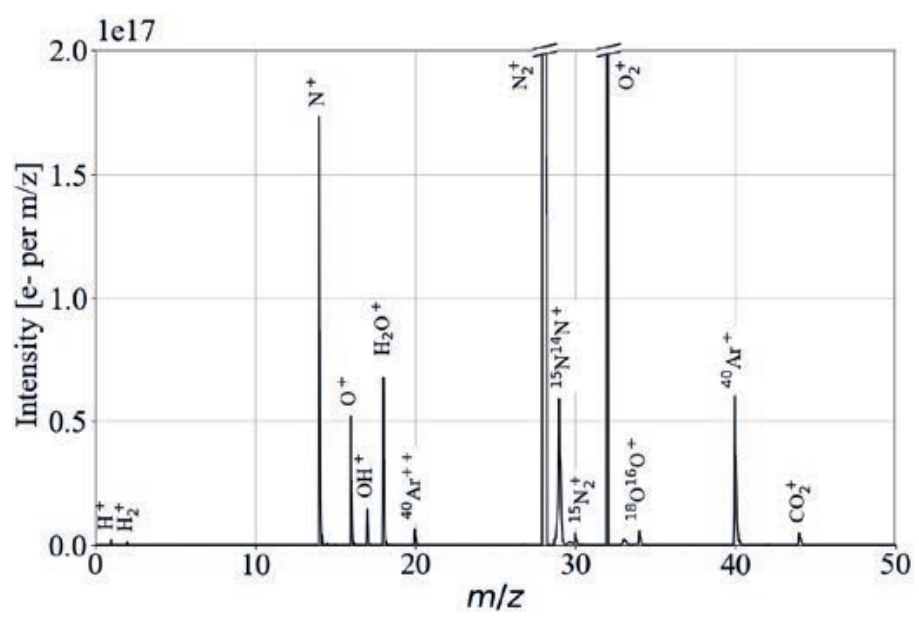

Fig. 8. Ambient air mass spectrum acquired with the lonTamer ${ }^{\mathrm{TM}} \mathrm{PS}-\mathrm{H}$ showing the species naturally found in the Earth's atmosphere: $\mathrm{H}_{2}, \mathrm{H}_{2} \mathrm{O}$, $\mathrm{N}_{2}, \mathrm{O}_{2}, \mathrm{Ar}, \mathrm{CO}_{2}$, some isotopologues (such as ${ }^{15} \mathrm{~N}^{14} \mathrm{~N},{ }^{15} \mathrm{~N}_{2}$, and ${ }^{18} \mathrm{O}^{16} \mathrm{O}$ ), and fragments due to the ionization method. The spectrum is displayed here only up to $\mathrm{m} / \mathrm{z} 50$; the lonTamer ${ }^{\mathrm{TM}}$ is however capable to measure compounds with $\mathrm{m} / \mathrm{z}$ up to 1200 .

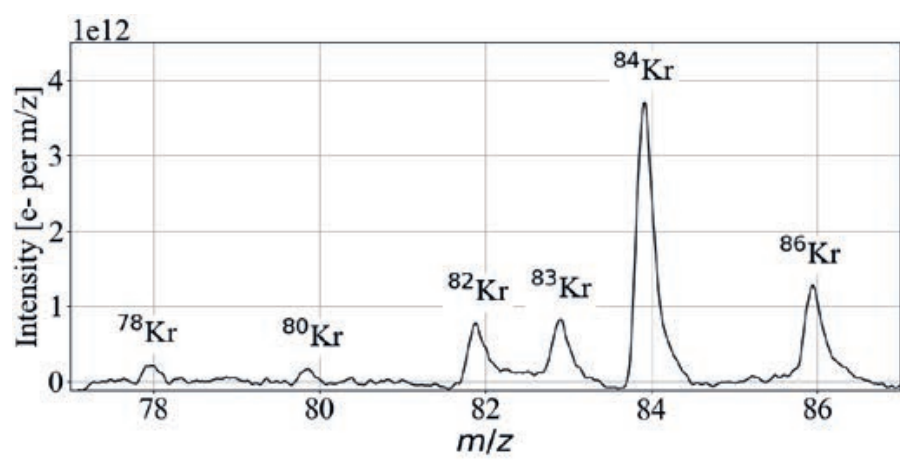

Fig. 9. Zoom on the krypton isotopes; data are from the same mass spectrum as the one displayed in Fig. 8.

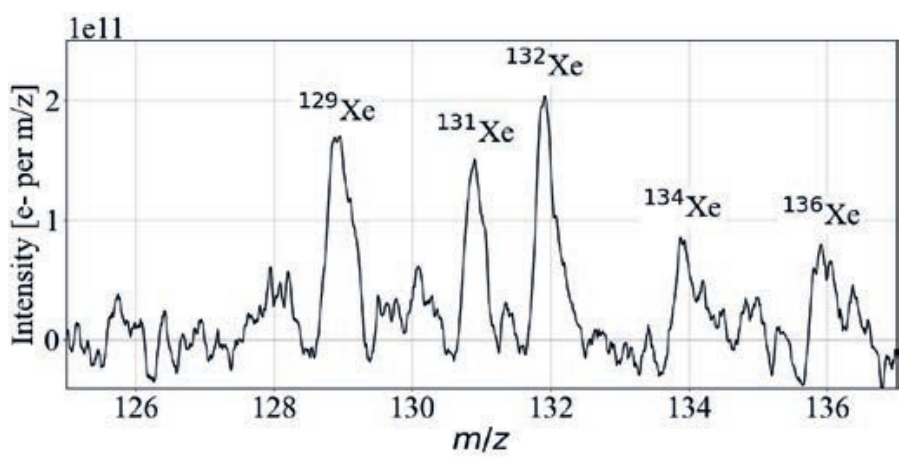

Fig. 10. Zoom on the xenon isotopes; data are from the same mass spectrum as the one displayed in Fig. 8.

All noble gases naturally present in the Earth's atmosphere can be identified in the spectrum, except for neon $(m / z=19.9924)$ whose identification is made difficult due to the presence at the same mass of the doubly charged ${ }^{40} \mathrm{Ar}(\mathrm{m} / \mathrm{z}=19.9806)$. In addition to the most abundant isotopes $\left({ }^{4} \mathrm{He},{ }^{40} \mathrm{Ar},{ }^{84} \mathrm{Kr}\right.$, and $\left.{ }^{132} \mathrm{Xe}\right)$, other isotopes with lower abundances can be identified (see Table 3); their calculated $\mathrm{m} / \mathrm{z}$ values correspond to the expected literature values. Only ${ }^{78} \mathrm{Kr}$ is found to have a too high $\mathrm{m} / \mathrm{z}$ value: this is explained by the presence of residual hydrocarbons in the vacuum chamber at about the same $m / z$, such as benzene $\left(\mathrm{C}_{6} \mathrm{H}_{6}, \mathrm{~m} / \mathrm{z}=78.0464\right)$.

The results of the data analysis are presented in the Table 2 and Table 3. The analysis consists in the integration of each peak in the spectrum, and in the correction of these values for the sensitivity of the IonTamer ${ }^{\mathrm{TM}}$ for the studied species. The sensitivity correction factors have been calculated based on previous calibration measurements performed with noble gases, in the same instrument configuration as the one used for the measurements of noble gases in air. These sensitivity factors are shown in Table 4.

The abundances shown in Table 2 are calculated with a decent accuracy, with deviations in the order of $10 \%$ to $20 \%$ compared with the literature values (except for helium which is discussed hereafter): the high sensitivity of the IonTamer ${ }^{\mathrm{TM}}$ for the species with heavy masses yields a high signal-to-noise ratio, reaching seven decades in High Gain mode with $100 \mathrm{~s}$ integration, and facilitates therefore their detection and quantification. Only helium is significantly overestimated; its error is explained by a low signalto-noise ratio due to a small ionization cross section and lower instrument sensitivity.

The isotopic ratios are also in agreement with the literature values, with a higher ratio for ${ }^{78} \mathrm{Kr}$ which confirms a contamination with hydrocarbons at $m / z=78$. It is worth noting that the peaks at $\mathrm{m} / \mathrm{z}$, values 133.90 and 135.91 , corresponding to the ${ }^{134} \mathrm{Xe}$ and ${ }^{136} \mathrm{Xe}$ isotopes, are worth $8.9 \mathrm{ppb}$ and $7.5 \mathrm{ppb}$ respectively.

In conclusion, within $10000 \mathrm{~s}$, the IonTamer ${ }^{\mathrm{TM}} \mathrm{PS}-\mathrm{H}$ successfully identified trace amounts of noble gases in air and was able to quantify species down to a few ppb concentration. Faster detections are also expected in a near future, as additional measurements have been conducted with a new detector operated with a gain approximatively 100 times higher in comparison to the current one, leading to integration times in the order of $1000 \mathrm{~s}$. A higher accuracy could thus be reached, when coupled with improved integration algorithms that are being developed as of the writing of this document.

\subsubsection{Low Pressure Measurements in Ultra-high Vacuum}

As described in section 2.2, the IonTamerTM DI and FA versions are capable of operating under a pressure range up to $1 \cdot 10^{-5}$ mbar. To demonstrate their capability to be quantitative also in a low pressure range, an IonTamer ${ }^{\mathrm{TM}} \mathrm{FA}-\mathrm{H}$ has been operated in the ultra-high vacuum facilities of CERN, with pressure ranging from $4 \cdot 10^{-9}$ mbar to $5 \cdot 10^{-7}$ mbar. The instrument has been operated in high emission (electron ionization with $70 \mathrm{eV}, 3 \mathrm{~s}$ integration 
Table 2. Calculated abundances of the noble gases $\mathrm{He}, \mathrm{Ne}, \mathrm{Ar}, \mathrm{Kr}$, and $\mathrm{Xe}$ compared with literature; the deviation to the literature value is shown in the far right column.

\begin{tabular}{crrr} 
Species & \multicolumn{3}{c}{ Natural abundance in air } \\
& This work & Literature $^{[12]}$ & $\begin{array}{c}\text { Deviation to } \\
\text { literature }\end{array}$ \\
$\mathrm{He}$ & $8.77 \mathrm{ppm}$ & $5.24 \mathrm{ppm}$ & $+67.4 \%$ \\
$\mathrm{Ne}$ & - & $13.2 \mathrm{ppm}$ & - \\
$\mathrm{Ar}$ & $1.02 \%$ & $0.934 \%$ & $+9.2 \%$ \\
$\mathrm{Kr}$ & $0.91 \mathrm{ppm}$ & $1.14 \mathrm{ppm}$ & $-20.2 \%$ \\
$\mathrm{Xe}$ & $77 \mathrm{ppb}$ & $87 \mathrm{ppb}$ & $-11.5 \%$
\end{tabular}

Table 3. Calculated isotopic ratios of the noble gases $\mathrm{Ar}, \mathrm{Kr}$, and $\mathrm{Xe}$, compared with literature.

\begin{tabular}{|c|r|r|r|}
\hline \multirow{2}{*}{ Isotope } & \multicolumn{3}{|c|}{ Isotopic ratio [\%] } \\
\hline${ }^{36} \mathrm{Ar}^{+11]}$ & 35.9670 & 0.35 & 0.30 \\
\hline${ }^{38} \mathrm{Ar}^{+}$ & 37.9622 & 0.08 & 0.05 \\
\hline${ }^{40} \mathrm{Ar}^{+}$ & 39.9618 & 99.57 & 99.65 \\
\hline${ }^{78} \mathrm{Kr}^{+}$ & 77.9198 & 2.07 & 0.38 \\
\hline${ }^{80} \mathrm{Kr}^{+}$ & 79.9158 & 2.07 & 2.43 \\
\hline${ }^{82} \mathrm{Kr}^{+}$ & 81.9129 & 11.46 & 11.66 \\
\hline${ }^{83} \mathrm{Kr}^{+}$ & 82.9136 & 11.35 & 11.60 \\
\hline${ }^{84} \mathrm{Kr}^{+}$ & 83.9109 & 54.59 & 56.60 \\
\hline${ }^{86} \mathrm{Kr}^{+}$ & 85.9101 & 18.45 & 17.32 \\
\hline${ }^{128} \mathrm{Xe}^{+}$ & 127.9030 & 2.64 & 1.91 \\
\hline${ }^{129} \mathrm{Xe}^{+}$ & 128.9042 & 26.76 & 26.61 \\
\hline${ }^{130} \mathrm{Xe}^{+}$ & 129.9030 & 4.81 & 4.11 \\
\hline${ }^{131} \mathrm{Xe}^{+}$ & 130.9045 & 18.87 & 21.47 \\
\hline${ }^{132} \mathrm{Xe}^{+}$ & 131.9036 & 27.79 & 27.04 \\
\hline${ }^{134} \mathrm{Xe}^{+}$ & 133.9048 & 10.61 & 10.23 \\
\hline${ }^{136} \mathrm{Xe}^{+}$ & 135.9067 & 8.53 & 8.64 \\
\hline
\end{tabular}

Table 4. Relative sensitivity to $\mathrm{N}_{2}$ of the lonTamer ${ }^{\mathrm{TM}} \mathrm{PS}-\mathrm{H}$ for the noble gases $\mathrm{He}, \mathrm{Ar}, \mathrm{Kr}$, and $\mathrm{Xe}$.

\begin{tabular}{|c|c|}
\hline Species & Sensitivity relative to $\mathbf{N}_{\mathbf{2}}$ \\
\hline $\mathrm{He}$ & 0.03 \\
\hline $\mathrm{Ar}$ & 1.03 \\
\hline $\mathrm{Kr}$ & 1.90 \\
\hline $\mathrm{Xe}$ & 2.76 \\
\hline
\end{tabular}

time) with injections of a calibration gas mixture composed of $20 \% \mathrm{H}_{2}, 10 \% \mathrm{He}, 20 \% \mathrm{CH}_{4}, 10 \% \mathrm{Ar}, 10 \% \mathrm{Kr}, 10 \% \mathrm{Xe}$, rest. (20\%) $\mathrm{N}_{2}$. Additional measurements have been performed in Spacetek Technology's facilities to cover the pressure range from $5 \cdot 10^{-7}$ mbar to $1 \cdot 10^{-5}$ mbar. In both cases, a bake-out was performed for $c a$. 30 hours at $130{ }^{\circ} \mathrm{C}$ (CERN measurements) or
$150{ }^{\circ} \mathrm{C}$ (Spacetek Technology measurements) and a warm-up time longer than one hour was maintained prior to injecting the gas mixture in the vacuum chamber.

The data from these measurements have been used to calculate the isotopic ratios for the krypton and xenon isotopes, shown respectively in Fig. 11 and Fig. 12. Literature values from the Commission on Isotopic Abundances and Atomic Weights (CIAAW) ${ }^{[13]}$ are also shown for comparison.

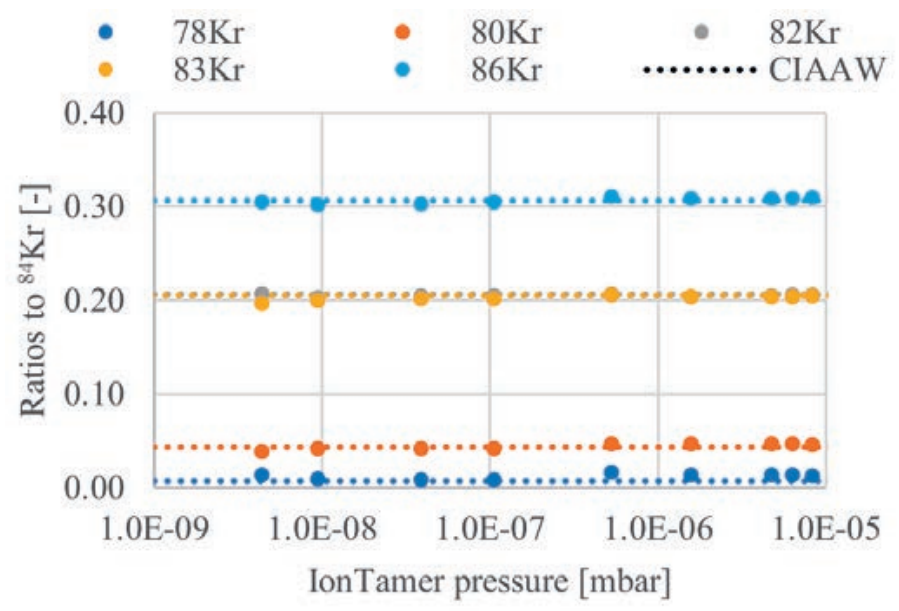

Fig. 11. Krypton isotopic ratios measured with the IonTamer'TM FA-H versus pressure.

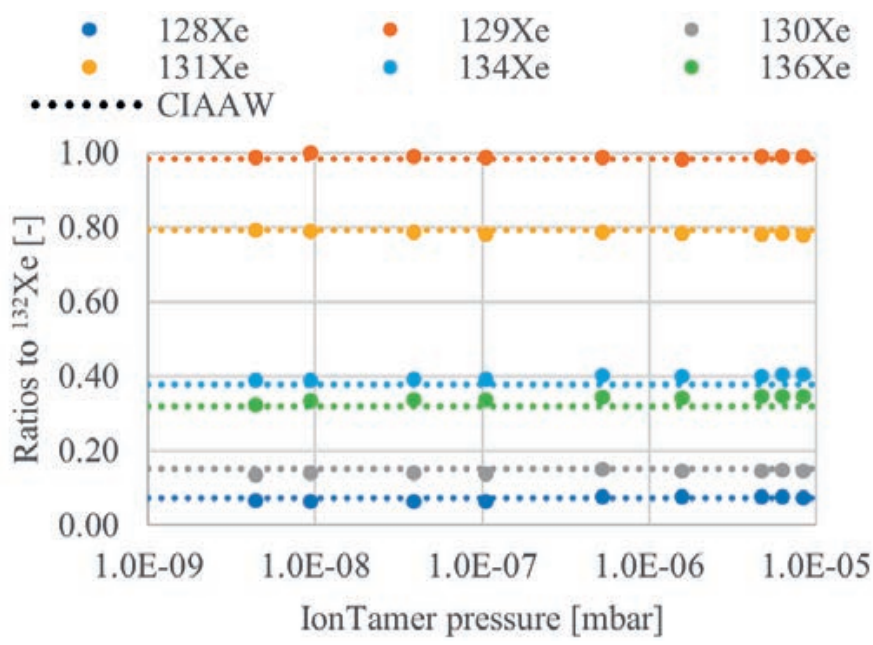

Fig. 12. Xenon isotopic ratios measured with the lonTamer ${ }^{\mathrm{TM}} \mathrm{FA}-\mathrm{H}$ versus pressure.

The isotopic ratios calculated both for the krypton and the xenon isotopes are well in accordance with the reference values from literature and demonstrate that the IonTamer ${ }^{\mathrm{TM}} \mathrm{FA}-\mathrm{H}$ is suitable for quantitative measurements in ultra-high vacuum.

\subsubsection{Real-time Process Control}

Process control in real time is a typical application where time-of-flight mass spectrometers bring significant benefits compared with quadrupole mass spectrometers, for example. The IonTamer ${ }^{\mathrm{TM}}$ instruments can be simply commanded to measure simultaneously all the species within the mass range, including high $\mathrm{m} / \mathrm{z}$ up to 1200 , with a high mass resolution.

As an example, we show in this section the results of measurements performed in a X-ray photoelectron spectroscopy 
(XPS) facility in Germany. The goal of these measurements was to monitor the gas composition of a process chamber during the XPS analysis of a process involving the production of graphene: with its many properties, graphene appears as a promising material in fields as various as electronics, photonics, energy storage, or for bioapplications. ${ }^{[14]}$ Production of graphene relies nowadays mostly on methods such as chemical vapor deposition, evaporation of silicon from silicon carbide, and simple exfoliation of graphene sheets from graphite. Other methods have been investigated, involving the adsorption upon heating of simple hydrocarbon precursors such as ethene $\left(\mathrm{C}_{2} \mathrm{H}_{4}\right)$ onto various catalysts. ${ }^{[15]}$ The process discussed in this section was carried on using a heated silver probe and has been monitored by an IonTamer ${ }^{\mathrm{TM}} \mathrm{FA}-\mathrm{H}$ connected to the process chamber in a pumping stage with a pressure lower than $10^{-5}$ mbar. Due to this mounting configuration, the concentration of graphene was expected to be low, therefore an integration time of 10 seconds has been chosen during the process monitoring. Although integration times as short as 0.1 second are possible with the IonTamer ${ }^{\mathrm{TM}}$ instruments, an integration time one hundred times longer allows to further increase the signal-to-noise ratio by a factor of ten. Time series showing the evolution of the abundances of ethene and of the graphene fragments over time are presented in Fig. 13 and Fig. 14, respectively.

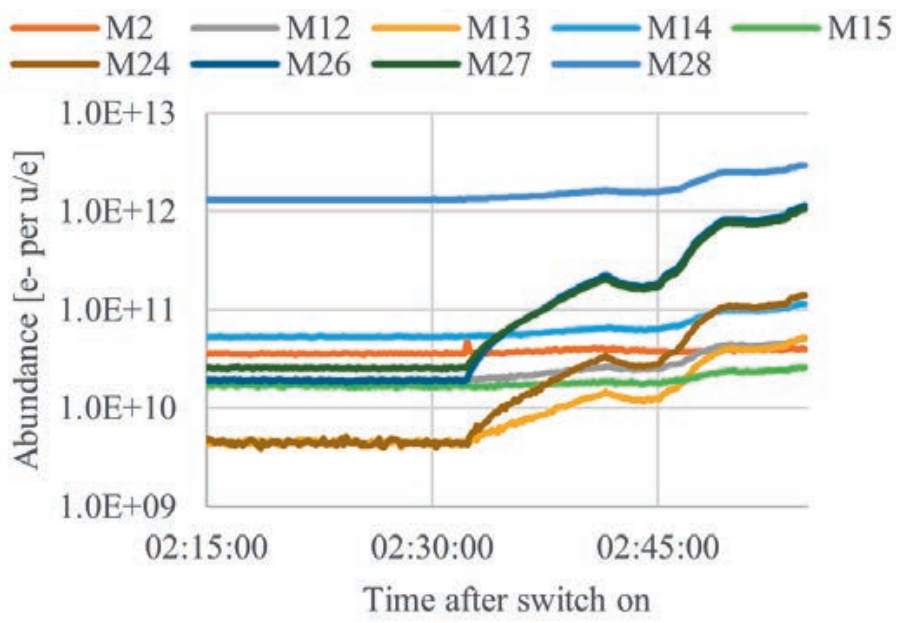

Fig. 13. Time evolution of the ethene fragments' abundances. All the fragments show a clear increase from the time when ethene is injected in the chamber, at $\mathrm{t}=02: 32: 00$.

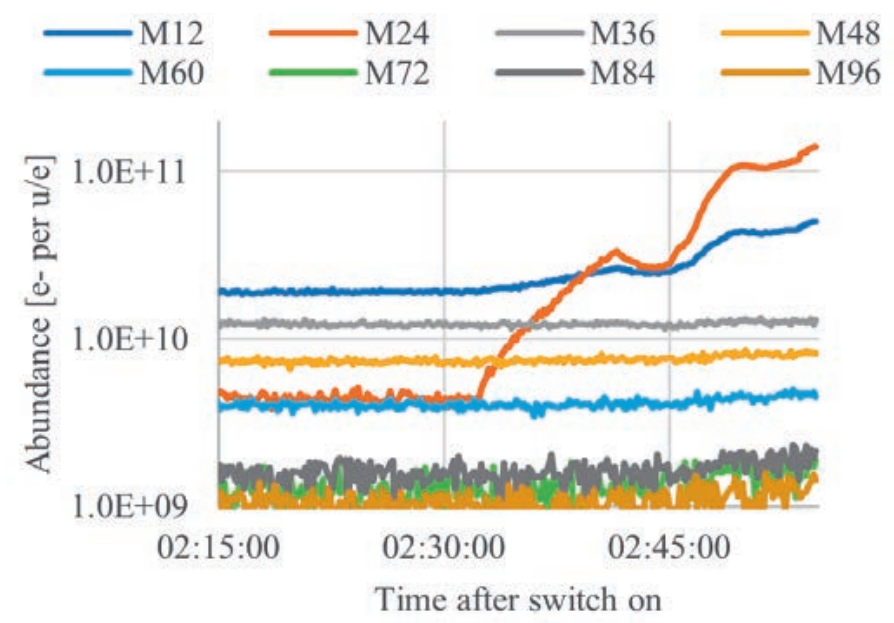

Fig. 14. Time evolution of the possible graphene fragments' abundances. Note: the fragments at $\mathrm{m} / \mathrm{z} 12$ and 24 are also fragments of ethene.
Fig. 13 shows the time evolution of the expected ethene fragments, i.e. $\mathrm{H}_{2}$ (M2), $\mathrm{C}$ (M12), $\mathrm{CH}$ (M13), $\mathrm{CH}_{2}$ (M14), $\mathrm{CH}_{3}$ (M15), $\mathrm{C}_{2}$ (M24), $\mathrm{C}_{2} \mathrm{H}_{2}$ (M26), $\mathrm{C}_{2} \mathrm{H}_{3}$ (M27), and $\mathrm{C}_{2} \mathrm{H}_{4}$ (M28). Note that other isotopologues might marginally contribute to the species listed above, as well as components mostly originating from residual gases in the chamber; for instance, residual $\mathrm{N}_{2}$ also contributes to M28, however its concentration is expected to remain stable during the process. A clear increase of all the fragments and therefore of the ethene concentration is observed at $\mathrm{t}=$ 02:32:00 after switch on, the time when ethene was injected in the process chamber.

Fig. 14 shows the time evolution of the masses where some graphene fragments are expected, i.e. $\mathrm{C}(\mathrm{M} 12), \mathrm{C}_{2}(\mathrm{M} 24), \mathrm{C}_{3}(\mathrm{M} 36)$, $\mathrm{C}_{4}$ (M48), $\mathrm{C}_{5}$ (M60), $\mathrm{C}_{6}$ (M72), $\mathrm{C}_{7}$ (M84), and $\mathrm{C}_{8}$ (M96). As $\mathrm{C}$ and $\mathrm{C}_{2}$ are also fragments of ethene, the observed increase in abundance of these species at $t=02: 32: 00$ after switch on is expected. Looking carefully at the time series of the other fragments, the slight increase after $\mathrm{t}=$ 02:45:00 in the abundances of M36, M48, and M60 and possibly of M72, M84 and M96, could be an indicator for the production of graphene.

Although very qualitative, these measurements show that the IonTamer ${ }^{\mathrm{TM}}$ is capable of identifying and tracking process species in real time. With such concentrations, a shorter integration time leading to a better spatial resolution would be possible to monitor even faster the evolution of the ethene's concentration in the process chamber. On the other hand, the observation of graphene could be made more quantitative simply by increasing the integration time for instance, thus increasing the signal-to-noise ratio and therefore making the detection of the graphene fragments clearer. Also, a better positioning of the instrument in the process chamber, allowing sampling closer to the process, would increase the signal quality.

\section{Perspective}

We presented in this work some examples of applications where the Spacetek Technology's first ever TOF-RGA intends to make a difference: by detecting complex molecules with heavy masses such as the FC5311 compound, as well as species with ppb abundances such as ${ }^{136} \mathrm{Xe}$ in air, the IonTamer ${ }^{\mathrm{TM}}$ instruments allow the fast detection of unexpected compounds under a total pressure ranging from at least $10^{-9}$ mbar to more than 1 bar. These capabilities offer a valuable way to monitor real-time processes such as wafer manufacturing or OLED-display manufacturing, where early detection of possibly unknown contaminants is key to ensure high quality and reliability of the process, or environmental science research, where identification and quantification of trace amounts of species down to a few ppb concentration is necessary.

With the IonTamer ${ }^{\mathrm{TM}}$ product series, we are providing novel time-of-flight mass spectrometers that are simple to operate and easy to integrate in proprietary process control tools, continuously and simultaneously measuring the entire mass range up to $\mathrm{m} / \mathrm{z}$ 1200 every $100 \mathrm{~ms}$ and with a high mass resolution.

With distributors already appointed in South Korea and in Israel, exclusive partnership for X-ray photoelectron spectroscopy instrument integration, and several test campaigns ongoing with semiconductor industry leaders, we believe that the IonTamer ${ }^{\mathrm{TM}}$ products are destined to have a promising industrial future while continuing to collaborate with renowned scientific research centers such as the CERN.

\section{Acknowledgements}

The authors would like to thank all the members of the Spacetek Technology AG's team working in mechanics, electronics, software, and management, whose expertise and everyday effort is the key to design, build, and test the outstanding high-performance mass spectrometers produced in the company. 
[1] A. A Osipov, G. A. Iankevich, A. B. Speshilova, A. A. Osipov, E. V. Endiiarova, V. I. Berezenko, I. A. Tyurikova, K. S. Tyurikov, S. E. Alexandrov, Sci. Rep. 2020, 10, 19977, https://doi.org/10.1038/s41598-020-77083-1.

[2] H. Noh, D. Kim, S. Han, China Semiconductor Technology International Conference, 2015, pp. 1-3, 2015.

[3] J. J. Chambers, K. Min, G. N. Parsons, J. Vacuum Sci. Technol. B 1998, 16, 2996, https://doi.org/10.1116/1.590332.

[4] J. Y. Hwang, D. J. Kim, N.-E. Lee, Y. C. Jang, G. H. Bae, Surf. Coat. Technol. 2007, 201, 4922, https://doi.org/10.1016/j.surfcoat.2006.07.081.

[5] W. C. Wiley, I. H. McLaren, Rev. Sci. Instrum. 1955, 26, 1150, https://doi.org/10.1063/1.1715212.

[6] K. K. Murray, R. K. Boyd, M. N. Eberlin, G. J. Langley, L. Li, Y. Naito, Pure Appl. Chem. 2013, 85, 1515.

[7] V. I. Karataev, B. A. Mamyrin, D. V. Shmikk, Sov. Phys. JETP 1972, 16.

[8] B. A. Mamyrin, V. I. Karataev, D. V. Shmikk, V. A. Zagulin, Soviet Phys. J. Exp. Theor. Phys. 1973, 37, 45.

[9] J. H. J. Dawson, M. Guilhaus, Rapid Commun. Mass Spectrom. 1989, 3, 155, https://doi.org/10.1002/rcm.1290030511.

[10] H.-J. Hübschmann, 'Handbook of GC/MS: Fundamentals and Applications', WILEY-VCH Verlag GmbH \& Co. KGaA Weinheim, 2nd ed., 2009.

[11] CIAAW, 'Atomic weights of the elements 2020', available online at www. ciaaw.org.
[12] Average composition of dry atmosphere: standard ISO 2533 - 1975.

[13] CIAAW, 'Isotopic compositions of the elements 2019', available online at www.ciaaw.org

[14] K. S. Novoselov, V. I. Fal'Ko, L. Colombo, P. R. Gellert, M. G. Schwab, K. Kim, Nature 2012, 490, 192, https://doi.org/10.1038/nature11458.

[15] B. Wang, M. König, C. J. Bromley, B. Yoon, M.-J. Treanor, J.A. Garrido Torres, M. Caffio, F. Grillo, H. Früchtl, N. V. Richardson, F. Esch, U. Heiz, U. Landman, R. Schaub, J. Phys. Chem. C 2017, 121, 9413, https://doi.org/10.1021/acs.jpcc.7b01999.

\section{License and Terms}

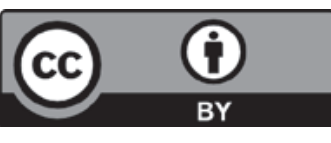

This is an Open Access article under the terms of the Creative Commons Attribution License CC BY 4.0. The material may not be used for commercial purposes.

The license is subject to the CHIMIA terms and conditions: (https://chimia.ch/chimia/about).

The definitive version of this article is the electronic one that can be found at https://doi.org/10.2533/chimia.2022.52 